\title{
RANCANGAN ANIMASI PENYULUHAN MATA PELAJARAN MATEMATIKA DASAR BAGI CALON GURU YANG AKAN MENGAJAR KE DAERAH TERTINGGAL
}

\author{
Cindy Alif, Achmad Syarief, Ifa Safira Sagir \\ (Email: cindysaja@ymail.com) \\ Program Studi Magister Desain \\ Fakultas Seni Rupa dan Desain \\ Institut Teknologi Bandung \\ Jl. Ganesha 10, Bandung, Indonesia
}

\begin{abstract}
ABSTRAK
Media pembelajaran berguna dalam membantu siswa dan guru untuk mengumpulkan pemahaman pengetahuan. Selanjutnya, media pembelajaran dapat berfungsi sebagai alat pembelajaran untuk mempersiapkan guru muda di berbagai daerah yang belum berkembang di Indonesia. Berdasarkan premis ini, penulis mengembangkan desain animasi pengetahuan mengajar matematika dasar bagi siswa di daerah yang belum berkembang di Indonesia. Tujuan dari desain media pembelajaran adalah untuk memberikan gambaran tindakan dalam mengajar matematika dasar dengan sumber daya pendidikan yang terbatas. Dalam proses desain, penulis menggunakan data gabungan dari observasi, wawancara, literatur, dan catatan lapangan untuk memahami realitas sosial mengajar matematika dasar di sekolah dengan sumber daya yang terbatas. Data diolah dibandingkan dengan teori belajar untuk mengembangkan isi media pembelajaran. Hal ini menghasilkan prototipe animasi sebagai media pembelajaran dan diproduksi sebagai narasi visual belajar matematika dasar di Papua sebagai studi kasus daerah yang ditargetkan. Menggunakan animasi sebagai seri isi media pembelajaran yang akan diterapkan juga pada mata pelajaran Indonesia, Bahasa Inggris, Ilmu Pengetahuan Alam, Ilmu Sosial, dan Seni.
\end{abstract}

Kata kunci: animasi; matematika dasar; media instruksi

\begin{abstract}
Instructional media are useful in assisting students and teachers to accumulate understandings on knowledge. Further, instructional media may serve as learning tool for young teachers prepared to be dispersed on various under-developed areas in Indonesia. Based on this premise, the authors develop and design an animation on the know-how of teaching basic math for students at under-developed areas of Indonesia. The purpose of instructional media design is to provide illustrative action in teaching basic math with limited educational resources. In the design process, the authors employed combined data of observation, interview, literatures, and field notes to understand social reality of teaching basic math at school with limited available resources. Processed data is compared with learning theory to develop contents of instructional media. It is resulted in a prototype of animation as an instructional media, produced as visual narrative of learning basic math at Papua as a case of targeted area. The animation is one of the series of instructional media contents, others are Indonesian, English, Natural Sciences, Social Sciences, and Arts.
\end{abstract}

Keywords: animation; basic mathematic; instructional media 


\section{PENDAHULUAN}

Guru memiliki tanggung jawab yang tinggi dalam proses pembelajaran peserta didik sehingga dalam upaya mencapai keberhasilan peserta didik memahami materi pelajaran, seringkali guru menggunakan media-media pembelajaran yang disesuaikan dengan materi pelajaran. Media pembelajaran sangat efektif dan efisien guna menyamakan persepsi atau sudut pandang guru dan siswa untuk memahami permasalahan dan mencari solusinya bersama-sama. Bagi guru yang mengajar di kota, media-media pembelajaran modern tentunya mudah didapat. Hal tersebut bertolak belakang dengan nasib guru yang mengajar di daerah tertinggal minim fasilitas. Namun, mereka dapat memanfaatkan benda-benda alamiah di sekitar untuk digunakan sebagai media pembelajaran. Adanya pendamping penyuluhan mengenai media pembelajaran sederhana tentu akan bermanfaat bagi calon guru ketika mereka terjun ke lapangan untuk mengajar di daerah tertinggal. Sebagai pendamping, penyuluhan ini akan disampaikan pada tahap pembekalan sebelum para calon guru dikirim ke daerah tertinggal.

Pemilihan konten penyuluhan media pembelajaran ditentukan berdasarkan mata pelajaran dasar. Landasan psikologis yang mendukung penyempurnaan pembelajaran dengan menggunakan media pada tingkat pelajaran dasar yakni teori Jean Piaget. Piaget berpendapat, rentang usia 7-11 tahun adalah tahapan operasional dimana seorang anak akan lebih memahami konsep pelajaran abstrak melalui benda-benda konkret. Mata pelajaran dasar yang dipilih sebagai prototip adalah matematika dasar. Matematika merupakan ilmu pengetahuan yang prinsip dasarnya bersifat abstrak, sehingga dibutuhkan media pembelajaran konkret.

Penyuluhan menggunakan media digital animasi dikarenakan media animasi saat ini sudah sangat berkembang hingga dimanfaatkan sebagai saluran penyuluhan. Animasi mampu membangkitkan minat, memicu emosi, menginspirasi orang-orang untuk berbagi konten dan bahkan membujuk mereka untuk terlibat atau dengan kata lain, animasi mendorong partisipasi. Berdasarkan sejarah perkembangannya, animasi dibagi kedalam 2 metode yakni animasi manual dan animasi komputer. Animasi manual merupakan bentuk animasi klasik yang dikerjakan secara manual atau digambar oleh tangan. Sementara animasi komputer adalah animasi yang dibuat dengan bantuan komputer. Animasi komputer dibagi lagi kedalam dua jenis yakni animasi komputer 2 dimensi (2D) dan animasi komputer 3 dimensi (3D). Ciri visual pada animasi 2D yakni gambar datar bergerak yang direpresentasikan dalam 
tinggi dan lebar dimensi, tetapi tidak menunjukkan kedalaman. Sementara itu, animasi 3D menghasilkan karakter yang lebih realistis yang diwakili dalam tiga dimensi yakni tinggi, lebar dan kedalaman. Akan tetapi, pembuatan animasi 3D membutuhkan biaya produksi yang tinggi dan secara teknis lebih sulit dibanding 2D. Hal tersebut menjadikan animasi komputer 2D saat ini masih diminati dan dapat ditemui tak hanya sebatas film bahkan dapat ditemui pada media iklan televisi hingga penyuluhan. Gaya visual atau gaya gambar dalam animasi beragam, mulai dari gaya yang realis hingga kartun. Penggunaan gaya gambar ke dalam animasi turut mempengaruhi konten yang ingin disampaikan pada animasi itu sendiri. Seperti pada teori segitiga Scott McCloud yang mengemukakan bahwa konten atau cerita dalam sebuah animasi memiliki pengaruh yang cukup besar terhadap gaya visual yang dibuat. Contoh pada animasi yang mengedepankan konten atau isi pesan, maka gaya visual cenderung menggunakan gaya ilustrasi kartun agar audiens fokus pada pesan yang disampaikan.

\section{METODE PENELITIAN}

Metode yang digunakan yakni metode penelitian kualitatif. Data yang terkumpul merupakan data hasil wawancara, studi dokumenter, catatan lapangan, studi literatur, hasil pemahaman realitas sosial dan kajian terhadap media penyuluhan dengan konten matematika dasar melalui video. Tujuan dari penelitian kualitatif ini adalah menghasilkan rancangan animasi sebagai media pendamping penyuluhan mata pelajaran matematika dasar bagi calon guru yang akan mengajar ke daerah tertinggal.

Teori yang digunakan dalam penelitian ini diantaranya; segitiga teori karakter Scott McCloud (2001) untuk pengembangan karakter serta menyesuaikan dengan konten bahasan penyuluhan yang bersifat serius. Sementara teori pendukung proses produksi animasi berdasarkan adaptasi proses produksi animasi Paul Wells (2006).

\section{PEMBAHASAN}

Daerah tertinggal adalah istilah yang digunakan untuk menandakan sebuah daerah yang memiliki tingkat kemajuan di bawah standar daerah secara nasional. Menurut Ja'far (2007), daerah tertinggal adalah sebuah daerah dengan keberadaan sumber daya alam dan sumber daya manusia namun miskin dalam pemenuhan sarana dan prasarana.

Terdapat 183 kabupaten yang tersebar di Indonesia dari Sabang sampai Merauke dan termasuk dalam kategori daerah tertinggal: 


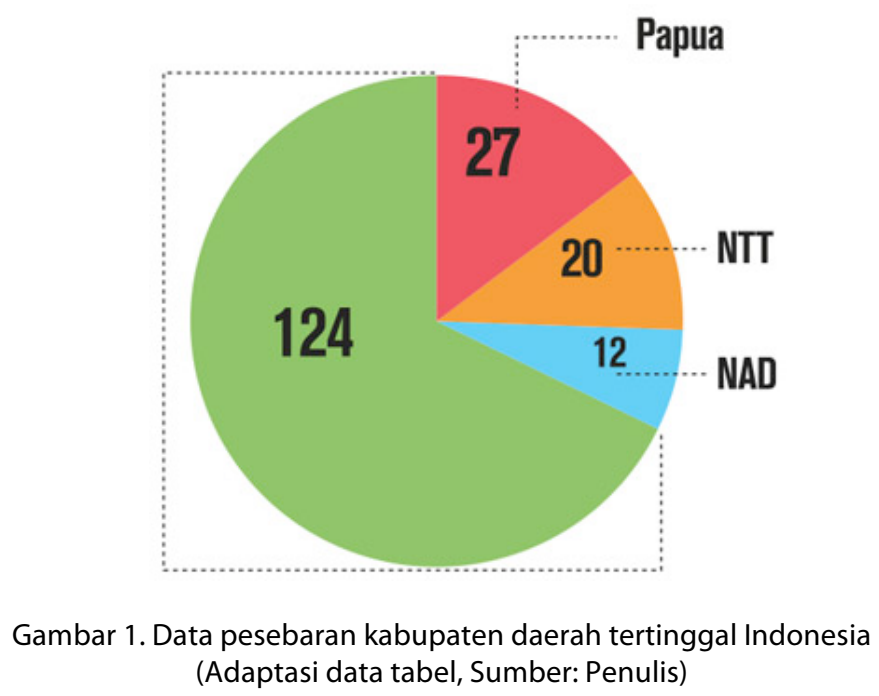

Sebanyak $70 \%$ berada di daerah Timur Indonesia. Papua menempati urutan pertama yang memiliki kabupaten daerah tertinggal terbanyak yakni 27 kabupaten, kemudian disusul Nusa Tenggara Timur sebanyak 20 kabupaten dan Nanggroe Aceh Darussalam sebanyak 12 kabupaten.

Berdasarkan hasil wawancara, permasalahan di dearah tertinggal dalam aspek pendidikan yang sering ditemui salah satunya adalah kurangnya fasilitas sekolah yang memenuhi standar (memadai). Keterbatasan fasilitas tersebut berpengaruh terhadap prestasi belajar siswa. Berbagai program dan usaha pembangunan daerah tertinggal dalam bidang pendidikan pada ujungnya akan menitikberatkan peranan guru yang mengajar disana agar mampu membuat murid mereka minimal mampu bertahan hidup dan bebas dari penindasan melalui bekal pendidikan yang mereka miliki.

\section{Media Pembelajaran Matematika Dasar Sederhana}

Penggunaan media pembelajaran sangatlah penting bagi hampir semua mata pelajaran pokok terutama matematika. Matematika adalah salah satu ilmu pengetahuan yang berkaitan dengan simbol-simbol dan prinsip dasarnya bersifat abstrak. Objek dasar pembelajaran matematika dibagi berdasarkan himpunan dan fungsi:

1. Aritmatika

- Himpunan: Bilangan-bilangan

(bil.bulat, bil.cacah, bil.prima, dsb.)

- Fungsi: Penjumlahan, pengurangan,

perkalian, pembagian, dsb. 


\section{Geometri}

- Himpunan: Bangun datar dan bangun ruang

- Fungsi: Pencerminan, pergeseran, perputaran, luas, volume dsb.

\section{Statistika}

- Himpunan: Kumpulan benda-benda

- Fungsi: Pengelompokkan bendabenda (dapat berupa benda sejenis) disajikan dalam tabel atau grafik

Prinsip dasar matematika diatas berkembang tingkat kesulitannya berdasarkan jenjang pendidikan. Ada 6 pandangan ahli dalam pembelajaran matematika yakni: (1) Matematika sebagai Seni, (2) Matematika sebagai Ilmu tentang Pola dan Hubungan, (3) Matematika sebagai Ilmu Deduktif, (4) Matematika sebagai Bahasa, (5) Matematika sebagai Ilmu tentang Struktur yang Terorganisasikan, dan (6) Matematika sebagai Aktifitas Manusia. Dari keenam cara pembelajaran matematika tersebut, penulis memilih 3 diantaranya dapat diterapkan sebagai media pembelajaran bagi peserta didik di daerah tertinggal yang minim fasilitas:

1. Matematika sebagai Seni

Seni merupakan satu hal yang sudah ada sejak peradaban manusia lahir. Salah satu seni yang paling mudah melekat dalam memori apresiatornya yakni seni musik. Musik dipercaya dapat memberikan stimuli bagi perkembangan otak. Lagu dengan lirik yang mengandung unsur matematika dasar dapat digunakan sebagai media pembelajaran bagi peserta didik di daerah tertinggal. Berikut beberapa judul lagu yang memiliki lirik bertema matematika dasar:
a) Dua Mata Saya
b) Sayang Semuanya
c) $1,2,3,4$
d) Satu Ditambah Satu
e) Tek Kotek Anak Ayam

2. Matematika sebagai Aktivitas Manusia

Sebagai salah satu aktivitas matematika dapat dibuktikan pada kegiatan yang dilakukan atau ditemui sehari-hari dan mengandung unsur matematika seperti permainan. Anakanak menyukai permainan, salah satu permainan tradisional yang mengandung unsur 
matematika dasar adalah permainan congklak. Anak-anak belajar berhitung sekaligus berpikir logis dan memahami taktik permainan.

3. Matematika sebagai Ilmu Deduktif

Sebagai ilmu deduktif matematika disimpulkan berdasarkan pola berpikir logis. Alat peraga merupakan media konkret yang membantu peserta didik memahami konsep abstrak matematika. Alat peraga modern yang umumnya digunakan diperkotaan contohnya sempoa (Aritmatika), balok geometri, kubus berhitung (statistika). Alat-alat peraga tersebut dapat digantikan dengan media-media sederhana yang mudah ditemui di daerah tertinggal seperti bebatuan kerikil, dedaunan, ranting-ranting pohon, buahbuahan atau biji-bijian.

Ketiga media sederhana untuk pembelajaran matematika dalam tabel akan digunakan sebagai konten pesan utama untuk penyuluhan.

\section{Konsep Perancangan}

Secara umum penyuluhan media pembelajaran akan disampaikan oleh satu karakter utama. Nama karakter diambil dari nama-nama khas mata pelajaran yang menarik dan memorable bagi audiens yakni; Jabar (diambil dari Aljabar). Cerita diawali dengan pengenalan latar belakang karakter utama. Kemudian la dikirim ke salah satu daerah tertinggal yang dipilih untuk perancangan animasi ini adalah Papua karena memiliki jumlah kabupaten daerah tertinggal paling banyak berdasarkan data. Selanjutnya, karakter utama menemukan permasalahan pada peserta didik dalam memahami pelajaran. Salah satu solusinya adalah dengan penggunaan media pembelajaran sederhana dari alam. Simpulannya murid dapat memahami pelajaran dan media pembelajaran juga mudah diperoleh disekitar tempat tinggal mereka. Pola kerangka cerita tersebut, nantinya akan digunakan sebagai pola dasar untuk menyusun cerita lain dengan konten penyuluhan mata pelajaran IImu Pengetahuan Alam, Ilmu Pengetahuan Sosial, Bahasa Indonesia, Bahasa Inggris dan Pendidikan Seni.

\section{Ide}

Dalam perancangan animasi ini penulis mengumpulkan ide yang bersumber dari kata kunci media pembelajaran, kemudian akan dibuat secara berseri sesuai dengan mata pelajaran dasar dengan menentukan matematika dasar sebagai mata pelajaran yang dijadikan contoh penyuluhan. 


\section{Tema}

Setelah menetapkan ide media pembelajaran selanjutnya penentuan tema. Penentuan tema biasanya mengerucut pada satu kata. Rancangan animasi ini bertemakan 'pendidikan' dengan maksud atau tujuan dari konten yakni memberikan penyuluhan mengenai informasi seputar dunia pendidikan bagi audiens.

\section{Logline}

Pada rancangan animasi ini, penulis menentukan logline berdasarkan cara pembuatan logline menurut Suyanto dan Yuniawan sebagai berikut:

Bagaimana jika seorang calon guru muda yang baru lulus dari pendidikan matematika tiba-tiba ditugaskan mengajar ke daerah tertinggal yang minim fasilitas serta kemampuan peserta didik kurang dan kemudian harus menyediakan media pembelajaran agar peserta didik memahami materi walaupun hanya dengan media sederhana.

\section{Sinopsis}

Cerita diawali dengan memperkenalkan tokoh utama mata pelajaran matematika yang diberi nama Jabar. Kemudian ia dikirim ke daerah tertinggal di Papua. Pemilihan Papua sebagai daerah tertinggal yang pertama dikunjungi, karena berdasarkan data pesebaran kabupaten daerah tertinggal, Papua memiliki paling banyak jumlah kabupaten yakni sebanyak 27.

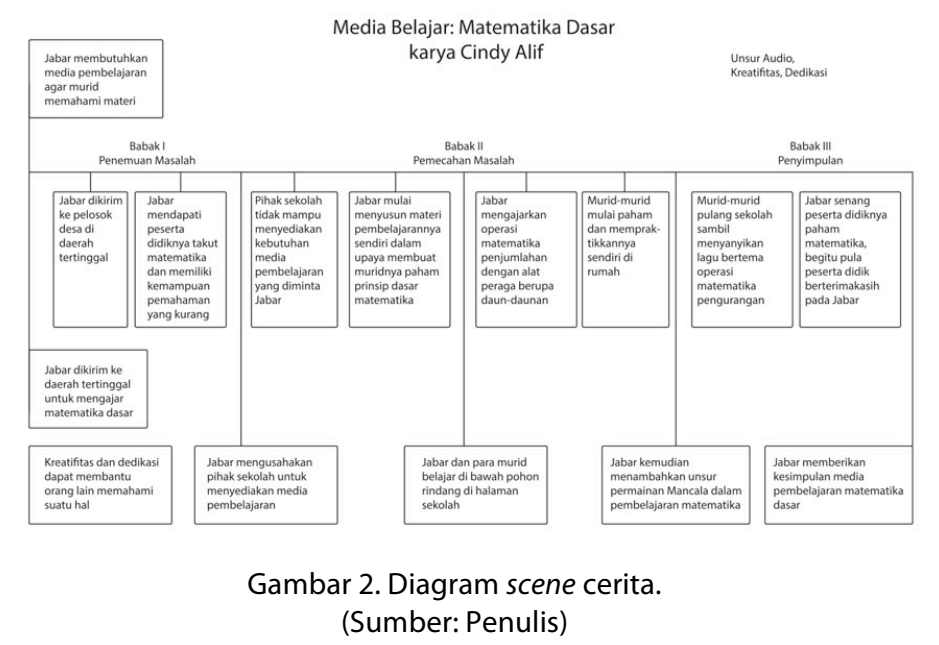

Sementara itu, Jabar akan menemukan bahwa kemampuan peserta didik memahami matematika dasar kurang, sehingga Jabar membuat pembelajaran matematika menjadi 
menyenangkan dan mudah bagi murid melalui media pembelajaran yang paling sederhana yang dapat dijumpai murid sehari-hari.

\section{Diagram Scene}

Diagram scene adalah bagian dari cara mempermudah penyusunan cerita, juga digunakan untuk pedoman penyusunan adegan. Dari sinopsis kisah Jabar, didapatkan diagram scene sebagai berikut: (Gambar 2)

\section{Studi Karakter}

Karakter cerita dibuat berdasarkan sistem cara ubah karakter pada teori segitiga karakter milik Scott McCloud yakni wujud transformasi karakter realis atau manusia asli ke wujud kartun. Wujud kartun pada teori tersebut dibagi dalam 4 fase, yakni: (1) Gaya gambar beberapa orang, (2) Gaya gambar ribuan orang, (3) Gaya gambar jutaan orang, (4) Gaya gambar (hampir) semua orang. Penjelasan keempat gaya gambar dan posisi mereka dalam aturan penggambaran karakter sebagai berikut:

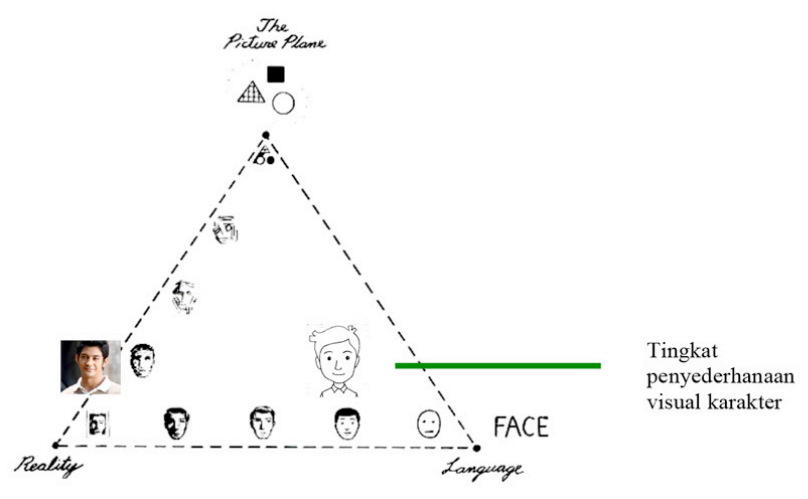

Gambar 3. Tingkat penyederhanaan karakter berdasarkan teori segitiga karakter Scott McCloud.

(Sumber: Penulis)

Dari tingkatan penyederhanaan karakter diatas, gaya gambar jutaan orang dipilih karena gaya tersebut tidak serta merta menyamaratakan karakter melainkan masih menunjukkan identitas. Identitas perlu untuk memberikan contoh pada audiens yang juga memiliki identitas masing-masing agar merasa menjadi bagian dari karakter. Gaya ilustrasi tersebut hingga saat ini juga masih mengalami perkembangan dan sedang marak digunakan. Berikut 
penokohan setiap karakter yang ada dalam penyuluhan dan transformasinya kedalam wujud ilustrasi:
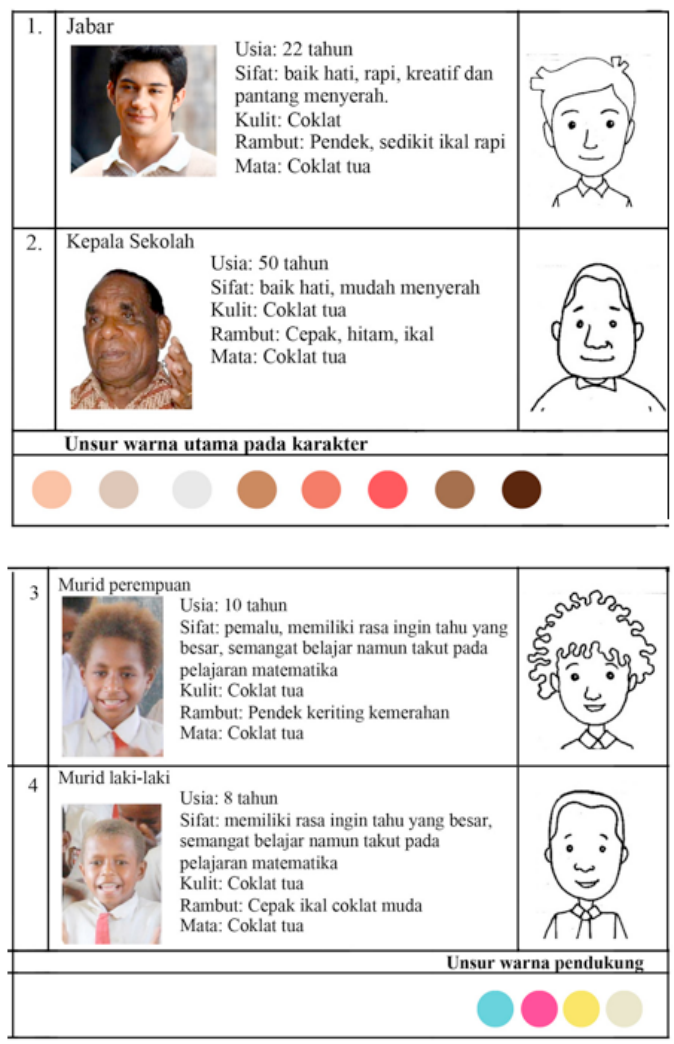

Gambar 4. Visualisasi karakter.

(Sumber: Data pribadi)

Warna-warna utama karakter merupakan warna adaptasi dari wujud karakter asli. Sementara warna pendukung merupakan warna-warna sekunder yang digunakan oleh karakter. Hasil studi karakter dan studi warna kemudian diolah secara digital sebagai berikut:

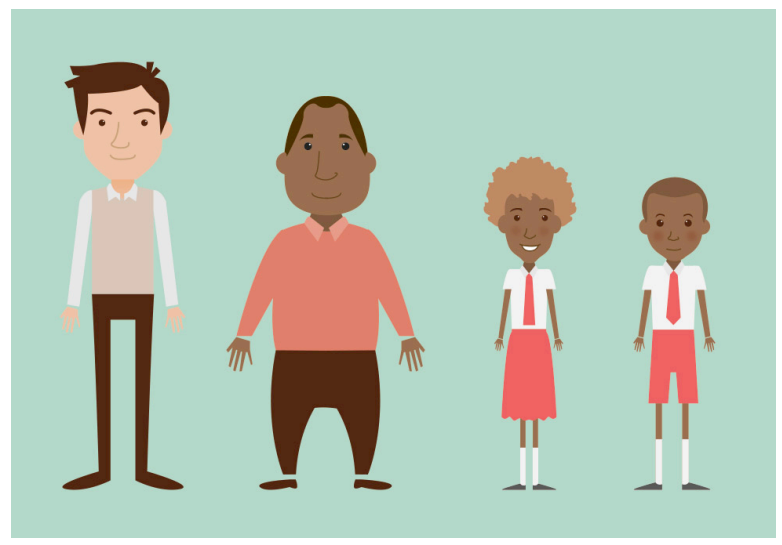

Gambar 5. Hasil digitalisasi karakter.

(Sumber: Data pribadi) 


\section{Tata Lingkungan}

Tata lingkungan dalam animasi penyuluhan ini bersifat sederhana sehingga fokus utama lebih kepada pesan yang disampaikan dan terkandung didalam cerita. Perancangan tata lingkungan menyesuaikan penyederhanaan karakter. Secara umum background menggunakan nuansa warna-warna yang menggambarkan mood. Sementara penggambaran lokasi menekankan kepada beberapa tempat seperti peta Indonesia untuk menunjukkan bahwa kejadian dalam cerita berada di Indonesia, kemudian penggambaran bangunan sekolah untuk memperlihatkan keadaan bangunan serta ruang belajar Jabar dan murid.

Referensi gambar yang digunakan untuk membuat tata lingkungan terdiri dari peta Indonesia, alam Papua, keadaan sekolah di Papua serta properti-properti pendukung mulai dari gedung sekolah hingga sampan sebagai alat transportasi antar pulau. Berikut referensi yang digunakan untuk menggambarkan tata lingkungan:

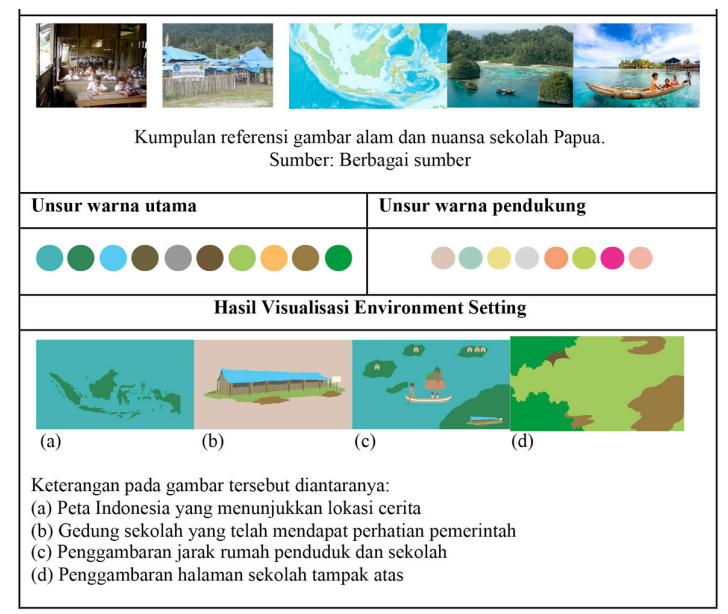

Gambar 6. Hasil visualisasi tata lingkungan.

(Sumber: Berbagai sumber)

Selebihnya gambaran lingkungan ditunjukkan oleh nuansa warna latar belakang, seperti warna latar abu-abu menggambarkan nuansa ruang kelas yang suram membuat proses pembelajaran tidak kondusif. Sementara latar warna cerah menunjukkan suasana hati senang para murid dalam belajar.

\section{Tipografi}

Unsur tipografi yang digunakan pada animasi yakni Akzidenz-Grotesk BQ dan McMuratti. Jenis tipografi ini memiliki font family yang lengkap untuk digunakan dalam penulisan teks yang bersifat serius atau informatif. Berikut karakter huruf Akzidenz-Grotesk BQ: 


\section{Akzidenz-Grotesk BQ \\ ABCDEFGHIJKLMNOPQRSTUVWXYZ \\ abcdefghijkImnopqrstuvwXyz 0123456789 !@\#\$\%^\&*()_+=-

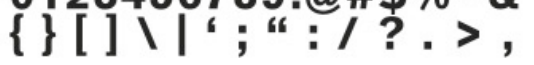

\section{Akzidenz-Grotesk BQ}

\section{ABCDEFGHIJKLMNOPQRSTUVWXYZ} abcdefghijklmnopgrstuvwxyz

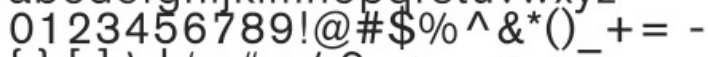

\{\}[]$\backslash \mid$; " : / ? . > , <

Gambar 7. Karakter huruf Akzidenz-Grotesk BQ

(Sumber: Data pribadi)

Aplikasi huruf-huruf ditampilkan dengan memainkan size pada setiap kata, berikut contoh penerapannya:

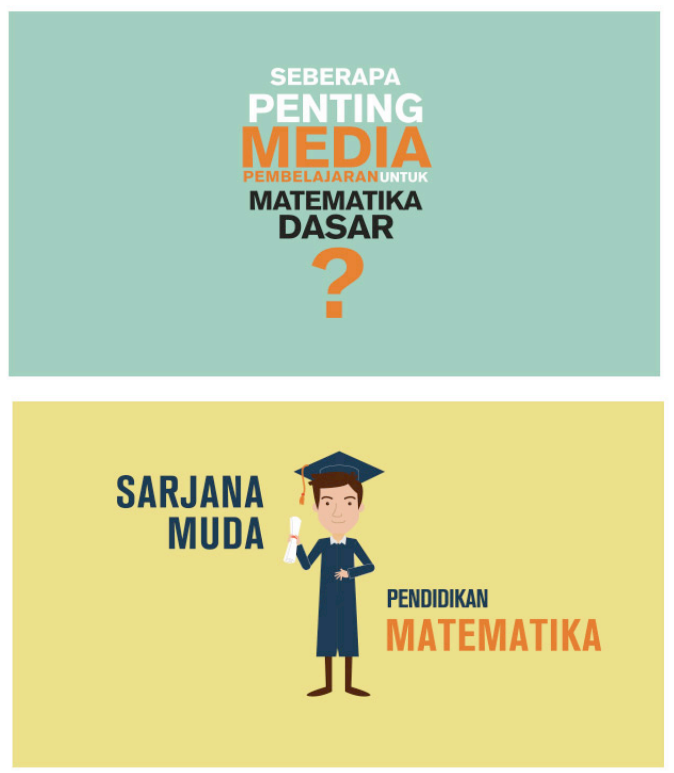

Gambar 8. Contoh aplikasi teks pada animasi. (Sumber: Data pribadi)

Unsur tipografi digunakan untuk membentuk kalimat inti yang terdapat hampir di semua adegan. Hal tersebut akan menambah fokus audiens hingga kepada inti dari pesan.

\section{Konsep Audio}

Audio merupakan elemen penting yang membuat penyuluhan dengan media animasi terasa 'hidup'. Audio yang muncul dalam penyuluhan terdiri dari 3 layer suara; 1) suara narator yang membacakan cerita, 2) efek suara, 3) background audio yang merupakan audio paling dasar mengiringi video berupa musik instrumen lokal asal Papua berjudul Teluk Wondama. 


\section{PENUTUP}

Penyuluhan merupakan salah satu bentuk komunikasi yang baik untuk menyampaikan informasi kepada calon guru yang akan mengajar di daerah tertinggal. Salah satu bentuk saluran penyuluhan yang saat ini sedang marak digunakan adalah animasi. Secara visual animasi memiliki daya tarik bagi audiens.

Proses penelitian ini menghasilkan rancangan animasi penyuluhan media pembelajaran matematika dasar. Konsep umum cerita diperoleh dari hasil studi literatur, wawancara, studi dokumenter, kajian pada penyuluhan dengan konten matematika yang menggunakan media penyaluran pesan sejenis video serta permasalahan-permasalahan umum di lapangan.

Sementara itu, konten cerita yang menekankan kepada penggunaan media pembelajaran matematika berupa alat peraga, permainan dan lagu adalah hasil penyederhanaan konsep dasar matematika diantaranya aritmatika, geometri dan statistika yang disesuaikan dengan kebutuhan matematika untuk tingkat dasar.

Karakter dan tata lingkungan sederhana adalah hasil aplikasi teori segitiga karakter Scott McCloud. Dengan demikian penekanan informasi lebih kepada isi pesan sementara animasi merupakan media pendukung. Pola penyampaian pesan penyuluhan yang digunakan pada prototype mata pelajaran matematika dasar ini akan digunakan untuk perancangan 5 seri mata pelajaran dasar lain diantaranya Bahasa Indonesia, Bahasa Inggris, IPA, IPS dan Seni.

\section{DAFTAR PUSTAKA}

Fleisher, Paul. 2013. Nutrisi Otak: 100+ Permainan yang Mengajar Anak-anak Berpikir. Jakarta: Indeks.

Ibrahim, Dr., M.Pd. dan Suparni, M.Pd. 2012. Pembelajaran Matematika: Teori dan Aplikasinya. Yogyakarta: SUKA-Press UIN Sunan Kalijaga.

Ja'far, Marwan. 2007. Infrastruktur Pro Rakyat: Strategi Infrastruktur Indonesia Abad 21. Jogjakarta: Pustaka Tokoh Bangsa.

McCloud, Scott. 2001. Understanding Comics (Memahami Komik). Jakarta: Kepustakaan Populer Gramedia.

Prihandoko, Drs. Antonius Cahya, M.App.Sc. 2005. Buku Rujukan PGSD Bidang Matematika: Memahami Konsep Matematika Secara Benar Dan Menyajikannya Dengan Menarik. 
Departemen Pendidikan Nasional Direktorat Jenderal Pendidikan Tinggi.

Sanaky, Hujair AH. 2009. Media Pembelajaran. Yogyakarta: Safiria Insani Press.

Sundayana, Rostina. 2013. Media Pembelajaran Matematika (untuk guru, calon guru, orang tua dan pecinta matematika). Bandung: Alfabeta.

Suyanto, M., Aryanto Yuniawan. 2006. Merancang Film Kartun Kelas Dunia. Yogyakarta: ANDI.

Wells, Paul. 2006. The Fundamentals of Animation. Switzerland: AVA Publishing SA.

\section{SUMBER ONLINE}

Animationforacause.org

BillZimmerman/http://www.wizmotions.com

http://www.youtube.com 